\title{
Dietary intake and gallbladder disease: a review
}

\author{
Marilyn Tseng ${ }^{1, *, \dagger}$, James E Everhart ${ }^{2}$ and Robert S Sandler ${ }^{3}$ \\ 'Department of Epidemiology, University of North Carolina at Chapel Hill, NC, USA: \\ ${ }^{2}$ National Institute of Diabetes and Digestive and Kidney Diseases, Bethesda, MD, USA: \\ ${ }^{3}$ Division of Digestive Diseases and Nutrition, Department of Medicine, \\ University of North Carolina at Chapel Hill, NC, USA
}

Submitted 8 May 1998: Accepted 5 January 1999

\begin{abstract}
Objective: Dietary intake has long been looked upon as a potentially modifiable risk factor for gallbladder disease (GBD), here defined as either having gallstones or having had surgery for gallstones. This paper reviews the epidemiological evidence for an association between dietary intake and GBD, focusing on six dietary factors that have received the most attention in studies in this area: energy intake, fatty acids, cholesterol, carbohydrates and fibre, calcium and alcohol. The objectives of this review are to evaluate the potential usefulness of altering the diet to prevent GBD and to consider future research in this area.

Design: We reviewed all English-language epidemiological studies on diet and cholelithiasis that were cross-sectional, cohort or case-control in design and that were indexed in the Medline database from 1966 to October 1997.

Results: A positive association was suggested with simple sugars and inverse associations with dietary fibre and alcohol. No convincing evidence was found for a role for energy intake or intake of fat or cholesterol. Variable means of ascertaining cases and inaccurate measurement of dietary intake may contribute to variation in results across studies.

Conclusions: Some specific components of the diet that may affect GBD include simple sugars, fibre and alcohol, but whether risk for GBD can be reduced by altering intake of a specific dietary factor has not been established. Although no specific dietary recommendations can be made to reduce risk of GBD per se, a 'healthy' diet aimed at reducing risk of other diseases might be expected to reduce risk for GBD as well.
\end{abstract}

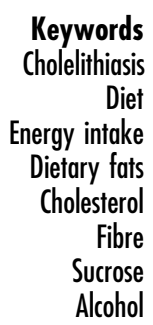

Gallbladder disease is an exceptionally common source of morbidity in the United States, where an estimated 20 million people either have gallstones or have had surgery for gallstones ${ }^{1}$. While most cases are asymptomatic, over 500000 cholecystectomies are performed annually, and over 800000 people are hospitalized because of gallstones, resulting in an annual cost of over US $\$ 5$ billion ${ }^{1}$. The most common manifestation of gallstones is biliary pain, but serious complications including gallbladder inflammation, pancreatitis and bile duct obstruction may result. Gallstones may also contribute to the development of gallbladder cancer ${ }^{1}$. Given the prevalence of the disease, measures towards preventing GBD could potentially lessen a large public health burden.

Diet has long been suspected as a modifiable risk factor for GBD, primarily because of indirect evidence from ecological studies and because of its link with obesity. Following a brief discussion of aetiology, this paper will discuss some methodological issues pertinent to studies on dietary intake and GBD and review the epidemiological evidence for an association between the two. Here, GBD is defined as either having gallstones or having had surgery for gallstones. The objectives of this review are to identify possible dietary measures to prevent GBD, and to make recommendations for future research in this area.

The studies we reviewed were identified by searching the Medline database from 1966 to October 1997; the key search terms were 'cholelithiasis' and 'diet'. Additional studies on diet and GBD were identified from the reference lists of articles identified from our Medline search or other review articles ${ }^{1-3}$. Our criteria for including studies in this review were: (i) language of the article had to be English; (ii) studies had to be case-control, cohort, or cross-sectional in design; (iii) the study outcome had to be incident or prevalent cholelithiasis, including gallstones, cholecystectomy, or both; and (iv) the study 'exposure' had to be dietary intake. Other aspects related to diet and known to be related to GBD such as weight loss ${ }^{4}$ or total parenteral nutrition ${ }^{5-7}$ were not considered, and 
studies on gallstone recurrence were also not included. In addition, although most studies do not distinguish among the different types of gallstones, conclusions from this review are presumed to apply to cholesterol stones, the more common type found in western and developed countries ${ }^{2}$. Finally, our review focuses on studies on humans or human populations. Although extensive research on gallstones has been conducted in animal models, no other animal besides the human is known to spontaneously develop cholesterol gallstones $^{8}$; thus, while animal models may offer information on specific aspects of the lithogenic process, their findings are not considered here.

\section{Pathogenesis}

Gallstones are solid masses that form in the gallbladder from cholesterol, bilirubin and calcium salts precipitated from the bile. The large majority of gallstones in western countries have cholesterol as their primary constituent, whereas a much smaller number are composed primarily of calcium salts of bilirubin and phosphate? . Three essential pathogenetic conditions precede the occurrence of cholesterol gallstones: lithogenic bile, gallbladder stasis and short nucleation time ${ }^{1}$.

Lithogenicity of the bile is determined by the relative concentrations of the three main components of bile; these are bile acids, phospholipids and cholesterol. Generally, lithogenic bile occurs with disruption of cholesterol homeostasis, leading to increased cholesterol secretion and subsequent cholesterol supersaturation of the bile ${ }^{10,11}$. Gallbladder stasis increases the opportunity for supersaturated bile concentrated in the gallbladder to form gallstones. Gallbladder stasis results when motility of the gallbladder is altered, leading to incomplete emptying of bile, increased fasting and residual volume of the gallbladder, and formation of biliary sludge, which enhances adherence of cholesterol crystals to form cholesterol gallstones ${ }^{11-14}$. Both supersaturated bile and sludge occur normally but often disappear without subsequent problems. However, a critical determinant of the formation of gallstones appears to be the activity of pronucleating and antinucleating factors which promote or inhibit cholesterol precipitation in supersaturated bile and, hence, affect nucleation time ${ }^{1}$; a difference in nucleation time appears to be a major discriminant between people with and without gallstones ${ }^{14}$. While lithogenic bile, gallbladder stasis and short nucleation time are often discussed separately, the three are not independent of each other ${ }^{12}$.

\section{Issues relevant to studies on diet and GBD}

Numerous studies have been published on diet and GBD, but whether or not altering dietary intake can alter disease risk has not been established. Two specific issues may contribute to the overall inconclusiveness of findings: problems in disease definition and ascertainment, and difficulties in measuring dietary intake. A discussion of these issues may provide background knowledge with which to evaluate studies on diet and GBD.

\section{Disease definition and ascertainment}

Disease definition and ascertainment in studies on GBD are particularly problematic because as many as twothirds of cases with gallstones are asymptomatic or silent ${ }^{15}$. Generally, asymptomatic cases can be identified only in screening studies, which use one of two primary techniques to detect the presence of gallstones: oral cholecystography and ultrasonography. In oral cholecystography, a contrast agent is administered to ensure opacification and radiographic visualization of the gallbladder. In ultrasonography, gallstones are detected as opacities in the gallbladder that reflect the ultrasound beam, produce a distal shadow and move with change in the individual's position, demonstrating the higher specific gravity of stones relative to bile ${ }^{16}$. Because of its non-invasiveness as well as its relative convenience, ultrasonography has become the standard method used to detect gallstones.

Since cholecystectomy is the most common procedure for treating gallstones, individuals who have undergone cholecystectomy, or surgical removal of the gallbladder, are also commonly included as gallstone cases and presumably represent cases with symptomatic gallstones. Non-screening studies, which include most case-control and prospective cohort studies, primarily identify clinically diagnosed, symptomatic cases, usually through hospital records or selfreport. Unless gallstones are confirmed by oral cholecystography or ultrasonography, however, clinically diagnosed cases may include individuals with conditions that mimic gallstone symptoms or who underwent surgery for other reasons, such as acalculous cholecystitis. Identification of cases through hospital records or self-report may also produce some detection bias if individuals with certain characteristics are more likely to be ascertained.

Depending on how disease was defined and cases were ascertained, findings from a given study may apply either to development of gallstones or more specifically to development of symptom-associated gallstones. If the former is of interest, complete screening is needed to identify all cases of gallstones, including those without symptoms. If the latter is of interest, then gallstones should be confirmed in the cases identified.

Distinguishing between factors contributing to gallstone formation and factors contributing to development 
of symptoms requires making two comparisons: symptomatic gallstone cases with silent gallstone cases, and silent gallstone cases with non-cases. Comparing the findings of screening and non-screening studies may also help distinguish the two types of factors because screening studies are weighed more heavily towards silent gallstone cases, while nonscreening studies would include primarily symptomatic cases. Inconsistent results and the potential for other types of biases, however, make such a comparison difficult. Hence, the relative contributions of risk factors in development and progression of the disease remain unclear.

The problem of disease ascertainment is exacerbated by disease heterogeneity. Studies are generally unable to distinguish between cholesterol and pigment stones although the two have distinctly different aetiologies and risk factors ${ }^{17}$. However, because cholesterol stones are the more common type of gallstones in western countries $^{2}$, most of our knowledge of the aetiology and epidemiology of gallstones applies specifically to cholesterol stones.

\section{Measurement of dietary intake}

A second limitation of studies on diet and GBD involves measurement of dietary intake. Measurement of intake is problematic in general given the difficulties involved in accurately recalling past diet. Categorizing individuals based on information from a 24-hour recall may also have led to substantial misclassification in some studies since the reported intake was unlikely to be representative of usual intake.

In addition, the relevant period of aetiological interest is unknown. In research using environmental carbon-14 to date gallstones, the average growth rate of gallstones was found to be $2.6 \mathrm{~mm}$ year $^{-1}$ for both asymptomatic and symptomatic cases, and the average latency period between gallstone formation and symptom development was almost 12 years; however, these analyses were based on only 15 cases $^{18}$. In general, the appropriate risk period of interest is unknown, and dietary exposures in previous studies may not have been measured for the appropriate period.

While the issues discussed above may make it harder to detect associations, other biases may lead to observation of spurious associations. In studies in which diet was assessed after disease diagnosis, case responses may have been biased, leading to inflated measures of association for some dietary factors. Cases may also have altered their diets as a result of symptoms or disease diagnosis, leading to "protopathic bias ${ }^{19}$. Even in screening studies in which untreated cases of gallstones were identified, cases could not be assumed to be completely asymptomatic, or their responses free of either recall or protopathic bias; in one screening study, as many as $40 \%$ of untreated gallstone cases were aware of their disease ${ }^{19}$.

\section{Dietary risk factors}

Diet has long been a suspected risk factor for gallstones. One source of evidence for this is the presumed link between cholesterol and gallstones. In fact, cholesterol overfeeding is the primary means of inducing supersaturated bile and cholesterol gallstones in animal models ${ }^{20}$. The observed relationship between obesity and GBD further implicates diet as an important risk factor. A strong positive association has been found consistently between GBD and various measures of obesity ${ }^{21-46}$, with some showing evidence of a doseresponse relation ${ }^{28,36,39,40,42}$.

Finally, ecological comparisons offer indirect evidence that diet may be an important factor in gallstone development. Early comparisons showed considerably higher prevalence of GBD in westernized than in nonwesternized countries ${ }^{47-49}$, and other research has shown that GBD prevalence can differ substantially between communities that differ in culture and in $\operatorname{diet}^{50}$. Observed trends in GBD over time also suggest a role for diet. Dietary changes, most notably a rise in caloric, lipid and animal protein intake ${ }^{51}$, may have contributed to the increase in GBD prevalence in European countries after World War $\mathrm{II}^{47}$. Secular changes in diet since World War II may also have contributed to an increase in cholesterol gallstones in Japan, where pigment stones were more common previously ${ }^{52}$.

The main dietary hypotheses proposed have focused on six dietary factors: energy intake, fatty acids, cholesterol, highly refined carbohydrates and dietary fibre, calcium and alcohol. Evidence for each of these is discussed below, and findings from cross-sectional, case-control and prospective cohort studies are summarized in Tables 1, 2 and 3, respectively.

\section{Energy intake}

Excessive energy intake is thought to increase risk for gallstones primarily by contributing to obesity. Obesity increases risk for gallstones by contributing to an elevated flux of cholesterol from the liver. Obesity has been associated with increased cholesterol synthesis, possibly in part through its association with hyperinsulinaemia, as well as increased biliary cholesterol secretion and cholesterol supersaturation of the bile b, $^{8}$.

A positive association between energy intake and GBD has been observed in relatively few studies $^{39,44,53-55}$ (Tables 1-3). Among the earliest reports of an association between energy intake and GBD is one by Sarles et al..$^{53}$, who found a 15\% higher mean caloric intake in gallstone patients than in 


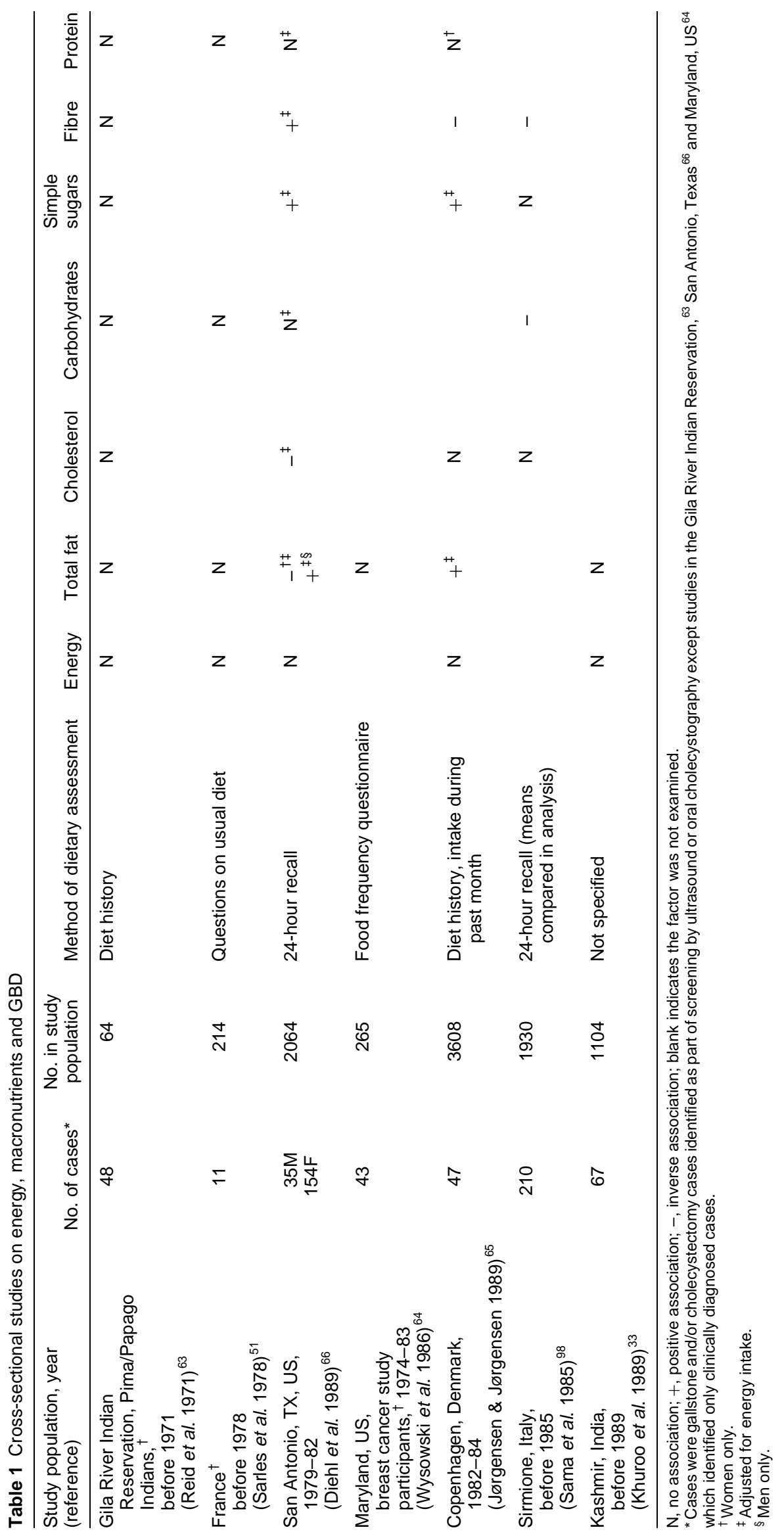




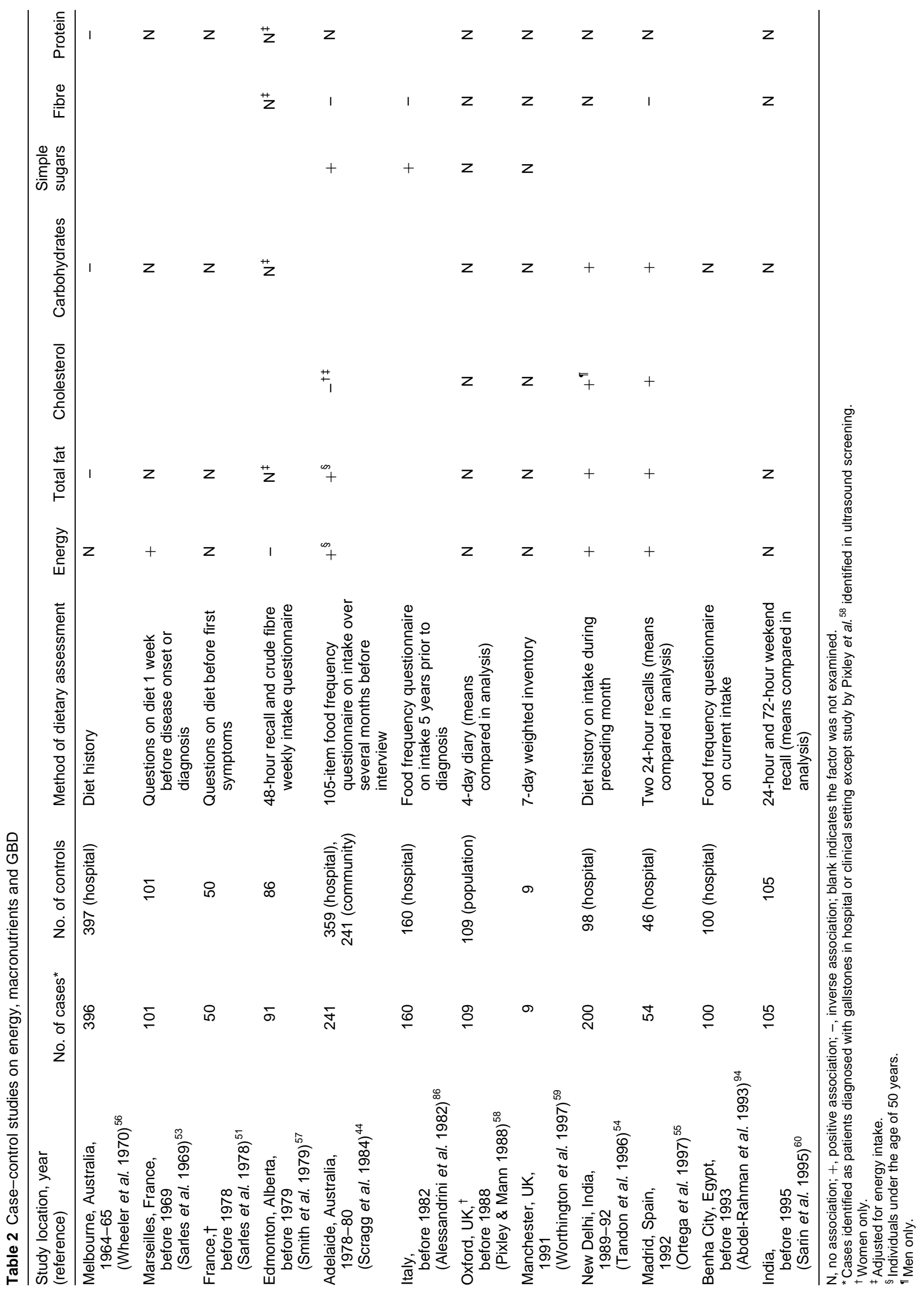




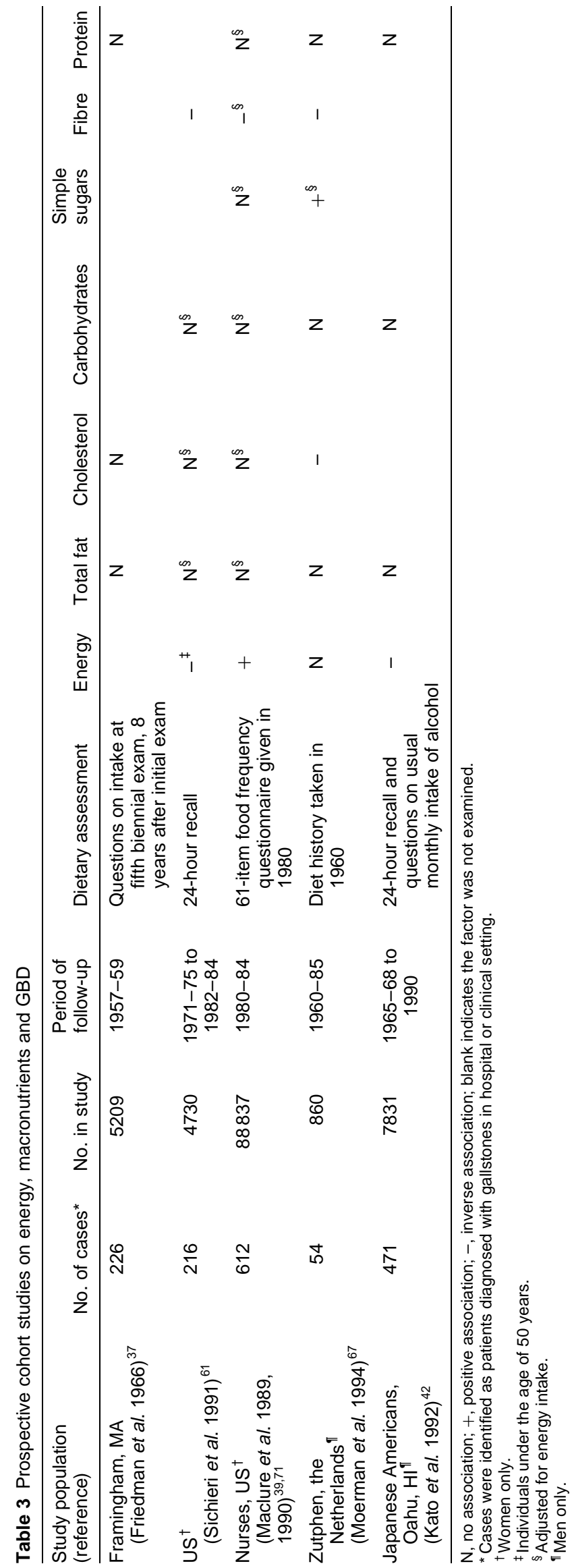

controls (Table 2). However, a considerably larger hospital-based case-control study published soon afterward found no difference in caloric intake between cases and controls ${ }^{56}$. Subsequent casecontrol studies also show inconsistent results, with some showing a positive association ${ }^{44,54,55}$ but others not $^{51,57-60}$. One relatively large case-control study conducted in Adelaide, Australia found a positive association but only among individuals under the age of 50 , suggesting that some individuals may be more susceptible to the disease than others ${ }^{44}$.

A positive association was also found in one prospective cohort study. In their study of a cohort of nurses, Maclure et al. ${ }^{39}$ found a significantly higher risk of gallstones in women in the highest quintile of energy intake relative to those in the lowest (Table 3). Risk was especially increased in non-overweight women, for whom risk in the highest quintile was over twice that of women in the lowest. Although two cohort studies found inverse associations between energy intake and $\mathrm{GBD}^{42,61}$, both categorized individuals based on a single 24-hour recall which may not have been representative of usual intake. Overall, results of diet-GBD studies provide little evidence of an association between energy intake and GBD. The null findings in the majority of studies reviewed may arise because energy intake is one of the most poorly measured aspects of the diet. The possibilities of underreporting, adoption of calorie-restricted diets ${ }^{42}$, or lower energy expenditure ${ }^{57}$ in obese individuals at higher risk for the disease may also contribute to null findings.

\section{Fatty acids}

Dietary fatty acids have also been suggested as a risk factor for gallstones, although the mechanism by which they may affect gallstone development is unclear ${ }^{8}$. Several mechanisms specific to different types of fat have been proposed, but changing either the type or the amount of fat in the diet in human feeding studies has not produced any consistent effects on bile cholesterol content or on gallstone occurrence ${ }^{8,62}$. High fat intake overall may also increase risk of gallstones by contributing to obesity.

Most cross-sectional studies ${ }^{33,51,63,64}$ show no association between fat intake and GBD (Table 1). However, in a large cross-sectional survey in Copenhagen, Denmark, Jørgensen et al. ${ }^{65}$ found a non-significant increase in GBD prevalence with higher percentage of energy from fat. In a study in San Antonio, Diehl et al. ${ }^{66}$ found a positive association for fat in men and an inverse association in women, but subjects were categorized based on a single 24-hour recall that may not have represented usual intake.

The majority of case-control studies are also null, 
but several tend to be fairly small ${ }^{51,53,57-60}$ (Table 2). Of the two largest case-control studies on diet and GBD, one hospital-based study found an inverse association $^{56}$, while the other, using both hospital and population controls, found a positive association among younger subjects ${ }^{44}$. None of the prospective cohort studies found an association between fat intake and GBD (Table 3).

In general, findings on dietary fat parallel results for total caloric intake and provide little evidence of an association with GBD. The studies, however, are similarly subject to biases discussed above for caloric intake, such as underreporting. Analyses on specific types of fat have not provided convincing evidence of a role for saturated, polyunsaturated or monounsaturated fatty acids ${ }^{55,59-61,63,65-69}$. In food-level analyses, some studies have found no association for fats or oils in diet ${ }^{45,70}$, including butter or margarine ${ }^{71,72}$, although others have $\mathrm{e}^{55,73}$. Positive associations have also been found for fried food consumption ${ }^{72}$ and preference for oily foods ${ }^{70}$.

Recent experimental studies have brought attention to fish oils as a protective factor ${ }^{74,75}$. No observational epidemiological studies have specifically investigated the association between fish oils and GBD. Among studies that identified types of foods associated with the disease, four ${ }^{55,72,73,76}$ found inverse associations with fish consumption, but three others did not ${ }^{67,70,71}$.

\section{Cholesterol}

Increased cholesterol intake has been hypothesized to contribute to bile cholesterol saturation. However, results of human feeding studies have been inconsistent $^{77-82}$. The possibility that dietary cholesterol may be a risk factor for gallstones has received even less support from observational epidemiological studies. No cross-sectional or cohort studies have found a positive association between cholesterol and GBD (Tables 1 and 3). Findings from case-control studies vary considerably, with one of the largest showing an inverse association ${ }^{44}$, two smaller, more recent studies showing a positive association ${ }^{54,55}$, and two others showing no association ${ }^{58,59}$ (Table 2). As far as examining specific high cholesterol foods, no observational studies have found a positive association between egg consumption and $\mathrm{GBD}^{55,67,70-72,76,83}$.

\section{Highly refined carbohydrates and fibre}

Consumption of highly refined carbohydrates coupled with low fibre intakes may increase risk of gallstone development. Insoluble fibre may protect against gallstone occurrence by speeding intestinal transit and reducing the generation of secondary bile acids such as deoxycholate ${ }^{84,85}$, which has been associated with increased cholesterol saturation of the bile ${ }^{8,62}$.

While studies on carbohydrate intake have been generally null, several studies have found GBD to be inversely associated with fibre intake and positively associated with simple sugar intake (Tables 1-3). In the cross-sectional study in Copenhagen, Jørgensen et al. ${ }^{65}$ found a non-significant trend of increased GBD prevalence with higher intake of refined sugar and a non-significant inverse trend for intake of dietary fibre (Table 1). A similar pattern of increased risk for sugar intake and decreased risk for fibre intake was also seen in two of the larger case-control studies, one in Adelaide, Australia ${ }^{44}$ and the other in Italy ${ }^{86}$ (Table 2), as well as in a prospective cohort study conducted in Zutphen, the Netherlands ${ }^{67}$ (Table 3).

In contrast to the Zutphen study, which found a twofold greater risk of clinically diagnosed gallstones for the highest tertile of sugar intake relative to the lowest, there was no association between gallstones and sucrose intake in the nurses' cohort $^{71}$ (Table 3). Whereas the nurses' study examined intake of sucrose specifically, other studies included mono- and disaccharides in their analyses of sugar intake ${ }^{44,67}$. Furthermore, analyses in the nurses' cohort were performed on energy-adjusted sucrose intake while sugar intake was unadjusted for energy in most other studies. A nonsignificant decrease in risk was observed for dietary fibre in the nurses' cohort even when adjusted for energy intake, with women in the highest quintile $80 \%$ as likely to develop symptomatic gallstones relative to those in the lowest ${ }^{71}$.

Overall, results across studies and study designs suggest that some aspect of a diet that is high in fibre or low in simple sugars may protect against GBD. It is notable that only one of 15 studies with information on fibre intake noted a positive association, and none of 10 studies with information on simple sugar intake noted an inverse association. Interestingly, however, one intervention study found that a diet high in fibre and low in refined carbohydrates did not reduce the risk of recurrence of gallstones after dissolution ${ }^{87}$.

At the food level, positive associations have been found for sugar or sugar products ${ }^{44,55,67,76}$, dates ${ }^{83}$, and pastries and cakes $^{88}$, although other researchers have not found positive associations for sugar-rich products ${ }^{45,71-73,76}$.

\section{Calcium and other vitamins and minerals}

Calcium has been hypothesized to protect against gallstones by binding secondary bile acids including deoxycholate in the small intestinal lumen, thus reducing the deoxycholate and cholesterol content of the bile. Few studies have examined the association between calcium intake and GBD and, thus, evidence for such an association is extremely limited. While three found an inverse association between dietary calcium and $\mathrm{GBD}^{24,55,67}$, others found no association ${ }^{53,59,61,63}$. An inverse association has also 
been observed with dairy or cheese products in some ${ }^{67,73,76}$ but not all ${ }^{55,70-72,83,88}$ studies.

There are few studies on other vitamins and minerals. Reid et al..$^{63}$ found no association for iron, magnesium, potassium or phosphorous. Ortega et al. ${ }^{55}$ looked at a large number of vitamins and minerals and found that cases had a lower intake of folate and magnesium and, among women, of vitamin C. Worthington et al. ${ }^{59}$ found that gallstone cases had a lower intake of 10 of 16 antioxidants examined in their study.

\section{Alcobol}

Moderate alcohol intake may protect against gallstone development, possibly through its association with reduced biliary cholesterol saturation and higher serum high density lipoprotein $(\mathrm{HDL})^{89,90}$. A substantial proportion of studies with information on alcohol intake have found evidence of an inverse association between alcohol drinking and GBD, including all of the 10 studies with the largest number of cases (Table 4). The alcohol-GBD association has been presented as an example of protopathic bias, with the disease leading to a reduction in the putative risk factor. Thijs et al. ${ }^{19}$ showed a decreased risk of clinically diagnosed gallstones in drinkers relative to non-drinkers in one case-control study but no association between alcohol and gallstones in three other studies designed specifically to minimize protopathic bias. While such bias is possible, however, it is less likely to have occurred in prospective cohort studies, all of which appear to show evidence of an inverse association (Table 4). Two separate follow-ups from the nurses' cohort found significant trends of decreased risk with increased alcohol consumption, with those consuming $\geqslant 15 \mathrm{~g}$ of alcohol a day only $70 \%$ as likely to develop symptomatic gallstones as non-drinkers ${ }^{39,41}$. In another large cohort study of Japanese American men, subjects in the highest category of alcohol consumption $(\geqslant 24.7 \mathrm{oz}$ alcohol month $^{-1}-27 \mathrm{~g}$ alcohol per day) were $80 \%$ as likely to develop GBD as non-drinkers ${ }^{42}$. In summary, findings from studies regardless of study design overwhelmingly support an inverse association between alcohol intake and GBD.

A few studies have found an apparent doseresponse relationship of decreased risk with increased alcohol intake $29,39,43,90$, although the association between gallstones and alcoholic liver cirrhosis ${ }^{91,92}$ suggests that excessive alcohol intake may increase risk of gallstones. Cirrhosis appears to be specifically associated with pigment stones rather than cholesterol stones ${ }^{17}$.

\section{Other foods or food patterns}

Two studies suggest that vegetarians may be at decreased risk for $\mathrm{GBD}^{27,93}$. Other studies also show evidence of a protective effect for vegetables ${ }^{53,73}$, vegetable fat $^{71,83}$, vegetable protein ${ }^{58,63,65,67,71}$, or crude fibre from vegetables ${ }^{57}$, although others have not ${ }^{51,55,59}$. $71,72,76,88,94$. Inverse associations have also been observed for olive oil ${ }^{88}$ and for the ratio of polyunsaturated fats to saturated fats ${ }^{65}$. A majority of studies fail to implicate meat as a risk factor. Although some have found positive associations for meat ${ }^{55,73}$, animal fat ${ }^{88,94}$ and animal protein ${ }^{59}$, most have not ${ }^{51,53,58,63,65,67,70-72,76,83,88}$.

Other specific foods of interest have included fruits $^{53,55,57,70-73,76,88}$, beans and pulses ${ }^{71,73,76,88}$ and caffeine $31,43,45,70,72,73,93$, but the few studies with information on these have had inconsistent findings and have not provided convincing evidence of their association with GBD.

\section{Conclusions and directions for future research}

Overall, the studies reviewed here do not provide strong evidence of a role for energy intake or intake of fat or cholesterol, but they suggest an association with simple sugars and inverse associations with dietary fibre and alcohol. Factors that are understudied are fish oils, calcium and antioxidants.

The failure to find consistent associations of diet to GBD is rather remarkable. Gallstones can be induced in animal models with only dietary manipulation. Also, bile plays a major role in the digestive process and its major constituents, including cholesterol, are derived from dietary fats. Much of the difficulty in studying associations between dietary factors and GBD arises from our limited ability to measure dietary intake accurately and for the relevant time period. An additional issue of concern is the appropriateness of a single-nutrient approach. Whereas laboratory research provides valuable information on the biological effects of specific dietary factors, and statistical tools can be used to disentangle their effects in observational studies, such findings are of limited relevance to actual dietary practice, especially since dietary factors can be highly intercorrelated. In this context, more useful information might be gained from investigating the combined effects of dietary factors or from quantifying the aggregate risk associated with dietary patterns.

In drawing conclusions on the association between dietary intake and GBD, the role of obesity should also be emphasized. If diet affects GBD occurrence by contributing to energy imbalance leading to excessive weight gain and obesity, then other factors related to energy balance should also be examined thoroughly. Physical activity, for example, has been found to be inversely associated with GBD in some studies ${ }^{31,42,95}$.

Other research could add to our understanding of the quality of case ascertainment in studies on GBD by addressing such issues as the proportions of clinically 


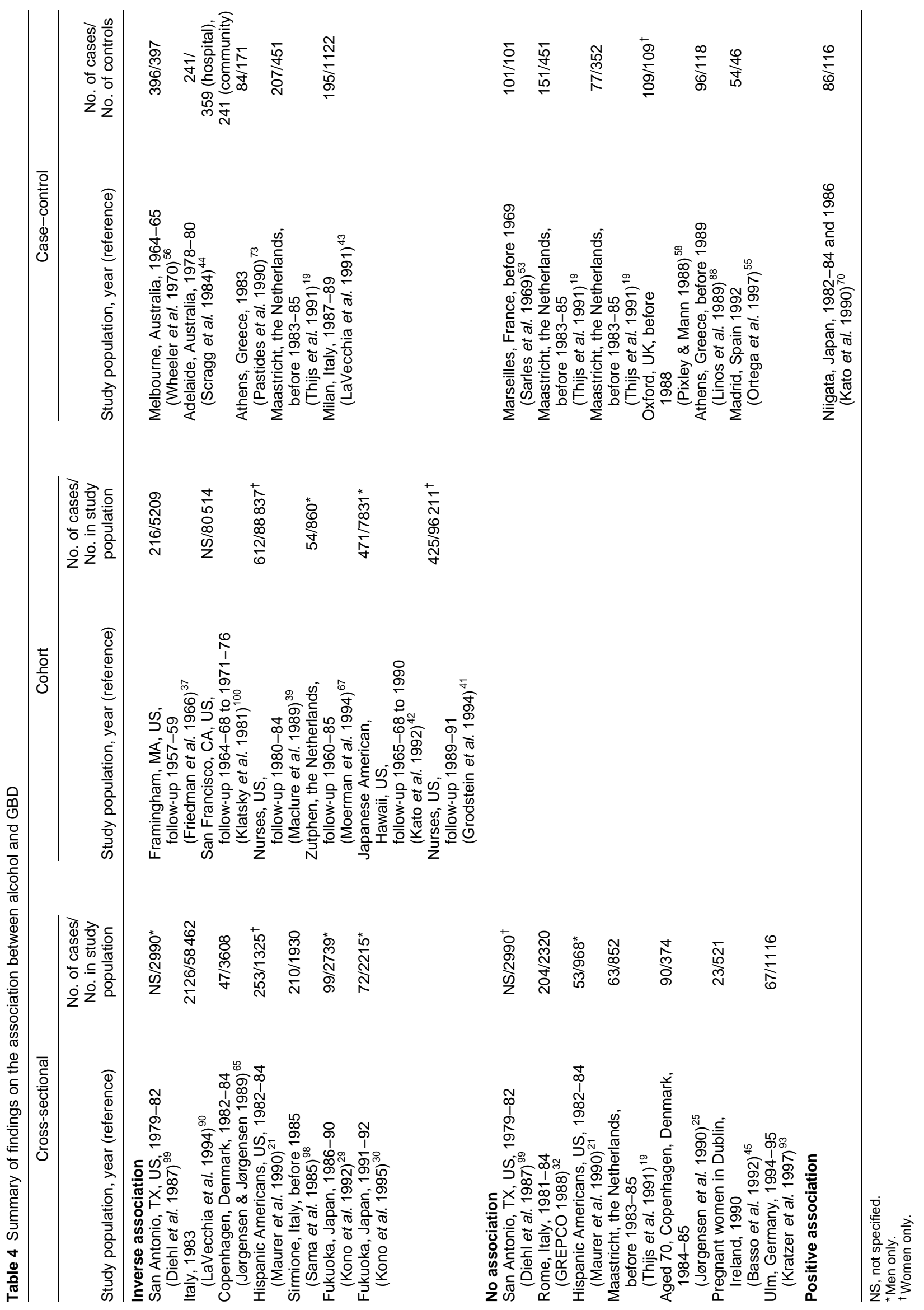


diagnosed cases or cholecystectomy cases who actually have or had gallstones. Future research should also distinguish asymptomatic from symptomatic gallstones in order to distinguish factors leading to development of gallstones from factors leading to progression to symptoms.

In sum, studies on diet and GBD overall suggest that dietary intake is associated with GBD, although the specific components of importance remain unclear. Dietary factors of particular interest are simple sugars, fibre, and alcohol. However, results of these studies cannot completely eliminate the possibility of confounding by other dietary or lifestyle factors, nor do they provide strong evidence that risk for GBD can be reduced by altering intake of a specific dietary factor. Although no specific dietary recommendations can presently be made to reduce the risk of GBD per se, implications of studies on GBD are at least consistent with recommendations to prevent other diseases. These include increasing the consumption of fibrerich vegetables, fruits and grains, minimizing the consumption of fats and sweets, and drinking alcohol in moderation ${ }^{96,97}$. Thus, a more generally 'healthy' diet that is promoted to reduce risk of other diseases might be expected to reduce risk for GBD as well.

\section{Acknowledgements}

The authors thank Dr Matthew Longnecker for his valuable comments on this manuscript. This research was supported in part by grants T32 DK07634 and P30 DK34987 from the National Institutes of Health.

\section{References}

1 Everhart JE. Gallstones. In: Everhart J, ed. Digestive Diseases in the United States: Epidemiology and Impact. NIH Publication No. 94-1447. Washington, DC: US Government Printing Office, 1994: 647-90.

2 Diehl AK. Epidemiology and natural history of gallstone disease. Gastroenterol. Clin. North Am. 1991; 20: 1-19.

3 Sama C, Labate AMM, Taroni F, Barbara L. Epidemiology and natural history of gallstone disease. Semin. Liver Dis. 1990; 10: 149-58.

4 Everhart JE. Contributions of obesity and weight loss to gallstone disease. Ann. Intern. Med. 1993; 119: 1029-35.

5 Messing B, Bories C, Kunstlinger F, Bernier JJ. Does total parenteral nutrition induce gallbladder sludge formation and lithiasis? Gastroenterology 1983; 84: 1012-19.

6 Roslyn JJ, Pitt HA, Mann LL, Ament ME, DenBesten L. Gallbladder disease in patients on long-term parenteral nutrition. Gastroenterology 1983; 84: 148-54.

7 Holzbach RT. Gallbladder stasis: consequence of longterm parenteral hyperalimentation and risk factor for cholelithiasis. Gastroenterology 1983; 84: 1055-8.

8 Hayes KC, Livingston A, Trautwein EA. Dietary impact on biliary lipids and gallstones. Annu. Rev. Nutr. 1992; 12: 299-326.

9 Cooper AD. Epidemiology, pathogenesis, natural history, and medical therapy of gallstones. In: Sleisenger MH, ed. Gastrointestinal Diseases: Pathophysiology, Diagnosis,
Management. Philadelphia: WB Saunders Company, 1993.

10 Cooper AD. Metabolic basis of cholesterol gallstone disease. Gastroenterol. Clin. North Am. 1991; 20: 21-46.

11 Carey MC. Pathogenesis of gallstones. Am.J. Surgery 1993; 165: 410-19.

12 Everson GT. Gallbladder function in gallstone disease. Gastroenterol. Clin. North Am. 1991; 20: 85-110.

13 Donovan JM, Carey MC. Physical-chemical basis of gallstone formation. Gastroenterol. Clin. North Am. 1991; 20: 47-66.

14 Holzbach RT, Busch N. Nucleation and growth of cholesterol crystals: kinetic determinants in supersaturated native bile. Gastroenterol. Clin. North Am. 1991; 20: 67-84.

15 Heaton KW, Braddon REM, Mountford RA, Emmitt PM. Symptomatic and silent gall stones in the community. Gut 1991; 32: 316-20.

16 Zeman RK. Noninvasive imaging of the biliary tract. In: Haubrich WS, Schaffner F, Berk JE, eds. Bockus Gastroenterology, Vol. 3. Philadelphia: WB Saunders Company, 1995: 2573-96.

17 Diehl AK, Schwesinger WH, Holleman DR Jr, Chapman JB, Kurtin WE. Clinical correlates of gallstone composition: distinguishing pigment from cholesterol stones. Am. J. Gastroenterol. 1995; 90: 967-72.

18 Mok HY, Druffel ER, Rampone WM. Chronology of cholelithiasis. Dating gallstones from atmospheric radiocarbon produced by nuclear bomb explosions. N. Engl.J. Med. 1986; 314: 1075-7.

19 Thijs C, Knipschild P, Leffers P. Does alcohol protect against the formation of gallstones? A demonstration of protopathic bias. J. Clin. Epidemiol. 1991; 44: 941-6.

20 Van der Linden W, Bergman F. Formation and dissolution of gallstones in experimental animals. Int. Rev. Exp. Pathol. 1977; 17: 173-233.

21 Maurer KR, Everhart JE, Knowler WC, Shawker TH, Roth HP. Risk factors for gallstone disease in the Hispanic populations of the United States. Am. J. Epidemiol. 1990; 131: 836-44.

22 Hanis CL, Hewett-Emmett D, Kubrusly LF et al. An ultrasound survey of gallbladder disease among Mexican Americans in Starr County, Texas: frequencies and risk factors. Ethnicity Dis. 1993; 3: 32-43.

23 Williams CN, Johnston JL, Weldon KLM. Prevalence of gallstones and gallbladder disease in Canadian Micmac Indian women. Can. Med. Assoc. J. 1977; 117: 758-60.

24 Williams CN, Johnston JL. Prevalence of gallstones and risk factors in Caucasian women in a rural Canadian community. Can. Med. Assoc. J. 1980; 122: 664-8.

25 Jørgensen T, Kay L, Schultz-Larsen K. The epidemiology of gallstones in a 70-year-old Danish population. Scand. J. Gastroenterol. 1990; 25: 335-40.

26 Rhomberg HP, Judmair G, Lochs A. How common are gall stones? BMJ 1984; 289: 1002.

27 Pixley F, Wilson D, McPherson K, Mann J. Effect of vegetarianism on development of gall stones in women. BMJ 1985; 291: 11-12.

28 Kono S, Kochi S, Ohyama S, Wakisaka A. Gallstones, serum lipids, and glucose tolerance among male officials of self-defense forces in Japan. Dig. Dis. Sci. 1988; 33: 839-44.

29 Kono S, Shinchi K, Ikeda N, Yanai F, Imanishi K Prevalence of gallstone disease in relation to smoking, alcohol use, obesity, and glucose tolerance: a study of selfdefense officials in Japan. Am. J. Epidemiol. 1992; 136 $787-94$.

30 Kono S, Shinchi K, Todoroki I et al. Gallstone disease among Japanese men in relation to obesity, glucose intolerance, exercise, alcohol use, and smoking. Scand. J. Gastroenterol. 1995; 30: 372-6. 
31 Jørgensen T. Gall stones in a Danish population. Relation to weight, physical activity, smoking, coffee consumption, and diabetes mellitus. Gut 1989; 30: 528-34.

32 Rome Group for the Epidemiology and Prevention of Cholelithiasis (GREPCO). The epidemiology of gallstone disease in Rome, Italy. II. Factors associated with the disease. Hepatology 1988; 8: 907-13.

33 Khuroo MS, Mahajan R, Zargar SA, Javid G, Sapru S. Prevalence of biliary tract disease in India: a sonographic study in adult population in Kashmir. Gut 1989; 30 201-5.

34 Barbara L, Sama C, Labate AMM et al. A population study on the prevalence of gallstone disease: the Sirmione study. Hepatology 1987; 7: 913-17.

35 Barbara L, Festi D, Frabboni $\mathrm{R}$ et al. Incidence and risk factors for gallstone disease: the 'Sirmione study'. Hepatology 1988; 8: 1256.

36 Khare M, Everhart JE, Maurer KR, Hill MC. Association of ethnicity and body mass index (BMI) with gallstone disease in the United States. Am. J. Epidemiol. 1996; 141 (Suppl.): S69.

37 Friedman GD, Kannel WB, Dawber TR. The epidemiology of gallbladder disease: observations in the Framingham study. J. Chron. Dis. 1966; 19: 273-92.

38 Layde PM, Vessey MP, Yeates D. Risk factors for gallbladder disease: a cohort study of young women attending family planning clinics. J. Epidemiol. Community Health 1982; 36: 274-8.

39 Maclure KM, Hayes KC, Colditz GA, Stampfer MJ, Speizer FE, Willett WC. Weight, diet, and the risk of symptomatic gallstones in middle-aged women. N. Engl. J. Med. 1989; 321: 563-9.

40 Stampfer MJ, Maclure KM, Colditz GA, Mansun JAE, Willett WC. Risk of symptomatic gallstones in women with severe obesity. Am. J. Clin. Nutr. 1992; 55: 652-8.

41 Grodstein F, Colditz GA, Hunter DJ, Mansun JE, Willett WC, Stampfer MJ. A prospective study of symptomatic gallstones in women: relation with oral contraceptives and other risk factors. Obstet. Gynecol. 1994; 84: 207-14.

42 Kato I, Nomura A, Stemmermann GN, Chyou PH. Prospective study of clinical gallbladder disease and its association with obesity, physical activity, and other factors. Dig. Dis. Sci. 1992; 37: 784-90.

43 La Vecchia C, Negri E, D’Avanzo B, Franceschi S, Boyle P. Risk factors for gallstone disease requiring surgery. Int. J. Epidemiol. 1991; 20: 209-15.

44 Scragg KR, McMichael AJ, Baghurst PA. Diet, alcohol, and relative weight in gall stone disease: a case-control study. BMJ 1984; 288: 1113-19.

45 Basso L, McCollum PT, Darling MR, Tocchi A, Tanner WA. A descriptive study of pregnant women with gallstones. Relation to dietary and social habits, education, physical activity, height, and weight. Eur. J. Epidemiol. 1992; 8 629-33.

46 Maringhini A, Marceno MP, Lanzarone F et al. Sludge and stones in gallbladder after pregnancy. Prevalence and risk factors. J. Hepatol. 1987; 5: 218-23.

47 Heaton KW. The role of diet in the aetiology of cholelithiasis. In: Capocaccia L, Ricci G, Angelico F, Angelico M, Attili AF, eds. Epidemiology and Prevention of Gallstone Disease. Lancaster: MTP Press, 1984.

48 Burkitt DP, Tunstall M. Gallstones: geographical and chronological features. J. Trop. Med. Hyg. 1975; 78: 140-4.

49 Brett M, Barker DJP. The world distribution of gallstones. Int. J. Epidemiol. 1976; 5: 335-41.

50 Malhotra SL. Epidemiological study of cholelithiasis among railroad workers in India with special reference to causation. Gut 1968; 9: 290-5.

51 Sarles H, Gerolami A, Bord A. Diet and cholesterol gallstones: a further study. Digestion 1978; 17: 128-34.
52 Nakayama F, Miyake H. Changing state of gallstone disease in Japan. Am. J. Surg. 1970; 120: 794-9.

53 Sarles H, Chabert C, Pommeau Y, Save E, Mouret H, Gerolami A. Diet and cholesterol gallstones: a study of 101 patients with cholelithiasis compared to 101 matched controls. Am. J. Dig. Dis. 1969; 14: 531-7.

54 Tandon RK, Saraya A, Paul S, Kapur BML. Dietary habits of gallstone patients in northern India. J. Clin. Gastroenterol. 1996; 22: 23-7.

55 Ortega RM, Fernández-Azuela M, Encinas-Sotillos A, Andrés P, López-Sobaler AM. Differences in diet and food habits between patients with gallstones and controls. J. Am. Coll. Nutr. 1997; 16: 88-95.

56 Wheeler M, Hills LL, Laby B. Cholelithiasis: a clinical and dietary survey. Gut 1970; 11: 430-7.

57 Smith DA, Gee MI. A dietary survey to determine the relationship between diet and cholelithiasis. Am. J. Clin. Nutr. 1979; 32: 1519-26.

58 Pixley F, Mann J. Dietary factors in the aetiology of gall stones: a case-control study. Gut 1988; 29: 1511-15.

59 Worthington HV, Hunt LP, McCloy RF, Maclennan I, Braganza JM. A pilot study of antioxidant intake in patients with cholesterol gallstones. Nutrition 1997; 13: 118-27.

60 Sarin SK, Negi VS, Dewan R, Sasan S, Saraya A. High familial prevalence of gallstones in the first-degree relatives of gallstone patients. Hepatology 1995; 22: 138-41.

61 Sichieri R, Everhart JE, Roth H. A prospective study of hospitalization with gallstone disease among women: role of dietary factors, fasting period, and dieting. Am. J. Public Health 1991; 81: 880-4.

62 Low-Beer TS. Nutrition and cholesterol gallstones. Proc. Nutr. Soc. 1985; 44: 127-34.

63 Reid SM, Fullmer SD, Pettigrew KD et al. Nutrient intake of Pima Indian women: relationships to diabetes mellitus and gallbladder disease. Am. J. Clin. Nutr. 1971; 24: 1281-9.

64 Wysowski DK, Goldberg EL, Comstock GW, Diamond EL. A study of a possible association between breast cancer and gallbladder disease. Am. J. Epidemiol. 1986; 123: 532-43.

65 Jørgensen T, Jørgensen LM. Gallstones and diet in a Danish population. Scand. J. Gastroenterol. 1989; 24: 821-6.

66 Diehl AK, Haffner SM, Knapp JA, Hazuda HP, Stern MP. Dietary intake and the prevalence of gallbladder disease in Mexican Americans. Gastroenterology 1989; 97: 1527-33.

67 Moerman CJ, Smeets FWM, Kromhout D. Dietary risk factors for clinically diagnosed gallstones in middle-aged men. Ann. Epidemiol. 1994; 4: 248-54.

68 Sturdevant R, Pearce M, Dayton S. Increased prevalence of cholelithiasis in men ingesting a serum-cholesterol-lowering diet. N. Engl. J. Med. 1973; 288: 24-7.

69 Miettinen M, Turpeinen O, Karvonen M, Paavilainen E, Elosuo R. Prevalence of cholelithiasis in men and women ingesting a serum-cholesterol-lowering diet. Ann. Clin. Res. 1976; 8: 111-16.

70 Kato I, Kato K, Akai S, Tominaga S. A case-control study of gallstones: a major risk factor for biliary tract cancer. Jpn J. Cancer Res. 1990; 81: 578-83.

71 Maclure KM, Hayes KC, Colditz GA, Stampfer MJ, Willett WC. Dietary predictors of symptom-associated gallstones in middle-aged women. Am. J. Clin. Nutr. 1990; 52: 91622.

72 Misciagna G, Leoci C, Guerra V et al. Epidemiology of cholelithiasis in southern Italy. Eur. J. Gastroenterol. Hepatol. 1996; 8: 585-93.

73 Pastides H, Tzonou A, Trichopoulos D et al. A case-control study of the relationship between smoking, diet, and gallbladder disease. Arch. Intern. Med. 1990; 150: 140912.

74 Berr F, Holl J, Jungst D et al. Dietary n-3 polyunsaturated fatty acids decrease biliary cholesterol saturation in gallstone disease. Hepatology 1992; 16: 960-7. 
75 Nestel PJ. Effects of n-3 fatty acids on lipid metabolism. Annu. Rev. Nutr. 1990; 10: 149-67.

76 Attili AF. Dietary habits and cholelithiasis. In: Capocaccia L, Ricci G, Angelico F, Angelico M, Attili AF, eds. Epidemiology and Prevention of Gallstone Disease. Lancaster, UK: MTP Press, 1984: 175-81.

77 DenBesten L, Connor WE, Bell S. The effect of dietary cholesterol on the composition of human bile. Surgery 1973; 73: 266-73.

78 Lee DWT, Gilmore CJ, Bonorris G et al. Effect of dietary cholesterol on biliary lipids in patients with gallstones and normal subjects. Am. J. Clin. Nutr. 1985; 42: 414-20.

79 Kern F Jr. Effects of dietary cholesterol on cholesterol and bile acid homeostasis in patients with cholesterol gallstones. J. Clin. Invest. 1994; 93: 1186-94.

80 Dam H, Prange I, Jensen MK, Kallehauge HE, Fenger HJ. Studies on human bile. IV. Influence of ingestion of cholesterol in the form of eggs on the composition of bile in healthy subjects. Z. Ernabrungswiss. 1971; 10: 178-87.

81 Andersen E, Hellstrom K. The effect of cholesterol feeding on bile acid kinetics and biliary lipids in normolipidemic and hypertriglyceridemic subjects. J. Lipid Res. 1979; 20: 1020-7.

82 Everson GT, McKinley C, Kern F Jr. Mechanisms of gallstone formation in women: effects of exogenous estrogen (Premarin ${ }^{\circledR}$ ) and dietary cholesterol on hepatic lipid metabolism. J. Clin. Invest. 1991; 87: 237-46.

83 Ahmed AF, Osman AK, Bustami AB, Aldirwish S, Bashir S. A pilot study of diet and gallstone formation in young Saudi women. J. R. Soc. Health 1993; 113: 57-9.

84 Marcus SN, Wheaton KW. Intestinal transit rate, deoxycholic acid and the cholesterol saturation of bile - three interrelated factors. Gut 1986; 27: 550-8.

85 Marcus SN, Wheaton KW. Effects of a new, concentrated wheat fiber preparation on intestinal transit, deoxycholic acid metabolism and the composition of bile. Gut 1986; 27: 893-900.

86 Alessandrini A, Busco MA, Gatti E, Rossi PA. Dietary fibres and cholesterol gallstones: a case control study. Ital. J. Gastroenterol. 1982; 14: 156-8.

87 Hood KA, Gleeson D, Ruppin DC, Dowling RH. Gall stone recurrence and its prevention: the British/Belgian Gall Stone Study Group's post-dissolution trial. Gut 1993; 9: 1277-88.
88 Linos AD, Daras V, Linos DA, Kekis V, Tsoukas MM, Golematis V. Dietary and other risk factors in the aetiology of cholelithiasis: a case control study. HPB Surg. 1989; 1 221-7.

89 Thornton J, Symes C, Heaton K. Moderate alcohol intake reduces bile cholesterol saturation and raises HDL cholesterol. Lancet 1983; 2: 819-22.

90 La Vecchia C, Decarli A, Ferraroni M, Negri E. Alcohol drinking and prevalence of self-reported gallstone disease in the 1983 Italian National Health Survey. Epidemiology 1994; 5: 533-6.

91 Fornari F, Civardi G, Buscarini E et al. Cirrhosis of the liver A risk factor for development of cholelithiasis in males. Dig. Dis. Sci. 1990; 35: 1403-8.

92 Acalovschi M, Badea R, Dumitrascu D, Varga C. Prevalence of gallstones in liver cirrhosis: a sonographic survey. Am.J. Gastroenterol. 1988; 83: 954-6.

93 Kratzer W, Kächele V, Mason RA et al. Gallstone prevalence in relation to smoking, alcohol, coffee consumption, and nutrition. Scand.J. Gastroenterol. 1997; 32 953-8.

94 Abdel-Rahman HA, Hafez AS, Maymoun NM et al. Risk factors of gallstone disease in a sample of patients in Benha City. J. Egypt. Public Health Assoc. 1993; 68: 205-27.

95 Leitzmann MF, Giovannucci E, Rimm EB, Stampfer MJ, Willett WC. Physical activity and the risk of gallstone disease in men. Ann. Intern. Med. 1998; 128: 415-25.

96 US Department of Agriculture/US Department of Health and Human Services. Nutrition and Your Health: Dietary Guidelines for Americans. Washington, DC: US Government Printing Office, 1990.

97 US Department of Agriculture/US Department of Health and Human Services. The Food Guide Pyramid. Washington, DC: US Government Printing Office, 1992

98 Sama C, Morselli Labate AM, Cornia GL et al. Dietary habit and cholelithiasis: results of an epidemiological study. Hepatology 1985; 5: 984.

99 Diehl AK, Haffner SM, Hazuda HP, Stern MP. Coronary risk factors and clinical gallbladder disease: an approach to the prevention of gallstones? Am. J. Public Health 1987; 77: $841-5$.

100 Klatsky AL, Friedman GD, Siegelaub AB. Alcohol use and cardiovascular disease: the Kaiser-Permanente experience. Circulation 1981; 64 (Suppl. III): 32-41. 